\title{
Kinetic Analysis of Some Chalcones and Synthetic Chalcone Analogues on the Fenton-Reaction Initiated Deoxyribose Degradation Assay ${ }^{1}$
}

\author{
Pál Perjési ${ }^{*}$ and Zsuzsanna Rozmer
}

Institute of Pharmaceutical Chemistry, University of Pécs, Rókus u. 2, H-7624 Pécs, Hungary

\begin{abstract}
Investigation of in vitro hydroxyl radical scavenging (antioxidant) effect 4-methoxychalcone (1a) and its cyclic analogues (2a-4a), as well as their hydroxyl substituted counterparts (1)-4b) was performed by means of the Fentonreaction initiated deoxyribose degradation assay in short term (10 minute) and long term (240 minute) experiments. The kinetic deoxyribose method provides possibility to investigate not only the short term antioxidant (hydroxyl radical scavenger) effect but the possible late prooxidant effect of the tested substances as well. In the short term studies compounds $\mathbf{2 a}, \mathbf{2 b}$ and $\mathbf{4 b}$ showed the most pronounced antioxidant effect. The long-term studies showed that the antioxidant activity of all the tested compounds but $4 \mathbf{a}$ can be well characterized by the short time determination of the thiobarbituric acid (TBA)-reactive substances (TBARS). Experiments in the presence of ethylenediaminetetraacetic acid (EDTA) resulted in a substantially reduced degradation of deoxyribose in each incubation. Similar to the respective experiment performed without EDTA, the TBARS level of the incubations with 4a showed an increase over the 60-120 minute period. The results demonstrated that complex forming activities that can modify microspeciation and reactivity of iron ions can lead to different short term antioxidant efficiency of the tested substances. Results of the long term incubations indicated that chemical transformation of the tested substances can result formation of derivatives that can initiate further redox activities under the experimental conditions.
\end{abstract}

Keywords: Chalcones, cyclic chalcone analogues, fenton-reaction, deoxyribose assay, prooxidant effect.

\section{INTRODUCTION}

Chalcones (1,3-diphenyl-2-propenones) (1) are intermediary compounds of biosynthetic pathway of a very large and widespread group of plant constituents known collectively as flavonoids [1]. Chalcones have been shown to possess antioxidant and anti-inflammatory properties in a variety of experimental systems $[2,3]$. The compounds have been shown to act as effective cell proliferation inhibitors, anti-tumor promoting and chemopreventive agents $[4,5]$.

Earlier we have investigated in vitro antineoplastic activity of several synthetic chalcones and the cyclic chalcone analogues, e.g., E-2-(X-benzylidene)-1-indanones (2), -tetralones (3) and benzosuberones (4) (Fig. 1A and 1B). The compounds were evaluated against P388, L1210, Molt 4/C8 and CEM cells as well as against approximately 60 further human tumor cell lines from nine different neoplastic diseases [6-8]. Besides the documented tumor cytotoxic effects, some of the above cyclic chalcone analogues were found to display outstanding CYP1A inhibitor activity [9].

Recently, we have investigated the effect of two of the above cyclic chalcone analogues, E-2-(4'-methylbenzyl-

\footnotetext{
*Address correspondence to this author at the Institute of Pharmaceutical Chemistry, University of Pécs, Rókus u. 2, H-7624 Pécs, Hungary; Tel: +36 72503 626; Fax: +36 72503 627;

E-mail: pal.perjesi@aok.pte.hu

${ }^{1}$ The paper is considered as Part $\mathrm{V}$ of the series E-2-Benzylidenecyclanones. Part IV: P. Perjési, J. Linnanto, E. Kolehmainen, E. Osz, E. Virtanen, J. Mol. Struct. 2005, 740 81-89..
}

idene)- and E-2-(4'-methoxybenzylidene)-1-benzosuberone (4a) on the cell cycle of Jurkat $\mathrm{T}$ cells. It was found that both compounds induced apoptosis and modified the cellular thiol status of the cells [10]. Investigation of effects of $\mathbf{4 a}$, and the hydroxyl-substituted analogs $\mathbf{1 b}-\mathbf{4 b}$ of the methoxy substituted derivatives (1a-4a) on isolated rat liver mitochondria showed the compounds to deplete reduced glutathione (GSH) and disrupt electron transport chain and energetic metabolism. Increased generation of reactive oxygen species (ROS) and possible covalent interaction with GSH was found to be as chemical events accompanied exposure of mitochondria of the investigated compounds [11, 12].

As a continuation of our previous works, in the present paper we report on investigation of in vitro hydroxyl radical scavenging (antioxidant) effect of the previously tested tumor cytotoxic 4-methoxychalcone (1a) and its cyclic analogues $\mathbf{2 a - 4 a}$, as well as their hydroxyl substituted counterparts (1b-4b) compared to the effect of quercetin (5) (Fig. 1A and 1B). Antioxidant effect of the compounds has been tested by means of the Fenton-reaction initiated deoxyribose degradation assay [13]. Degradation of deoxyribose is supposed to be the result of attack of the Fenton-reaction generated hydroxyl radicals (HO-), which results in formation of carbonyl fragments [14] that - on heating with TBA at low $\mathrm{pH}$ - generate a pink chromogen with absorption maximum at $532 \mathrm{~nm}$ [13]. Testing of antioxidant effect (hydroxyl radical-scavenging potential) is based on the competitive reaction of deoxyribose and the tested antioxidant with the reactive hydroxyl radicals [13]. 
Hydroxyl radicals (HO) formed in Fenton-type reactions are reported to react with phenol to generate isomeric dihydroxybenzene derivatives [15]. Since further oxidation (redox cycling) of the formed dihydroxy derivatives could generate reactive oxygen species (ROS), phenolic antioxidants could cause oxidative stress as a result of a series of spontaneous and enzyme catalyzed reactions [16, 17]. Such a mechanism can not be excluded for explanation of the observed prooxidant effect of the previously tested hydroxychalcones (1b-4b) [12]. To test this possibility we applied a modified version of the previously reported kinetic deoxyribose degradation assay [18], which can provide information not only on the immediate antioxidant action but on the possible late prooxidant effect of the investigated compounds as well [19]. Composition of the incubations and details of generation of TBARS were optimized based on the results of Winterbourn [20].

For comparison, we have performed the experiments in the presence of and without addition of ethylenediaminetetraacetic acid (EDTA) to the incubation mixtures. Addition of EDTA results in formation of iron(II)-EDTA complex [21], whose Fenton-activity could result in degradation of EDTA [22]. In the absence of EDTA, a portion of the iron ions is complexed by deoxyribose [23]. In these so called "site-specific" Fenton reactions hydroxyl radicals react immediately at the place where there are formed. Accordingly, compounds with ligand properties compete for the iron ions with the deoxyribose molecules and thus decrease degradation caused by the iron-catalyzed hydroxyl radical attack.

Quercetin (5) has received considerable attention because of its overwhelming presence in foods. The compound may aid in the prevention of several degenerative diseases (e.g., cancer, atherosclerosis, chronic inflammation) by preventing lipid peroxidation [24]. Quercetin (5) is well known as an efficient reducing agent and chelator of transition metals
[25]. Scavenging of free radicals and chelation of iron ions both contribute to the antioxidant activity of the compound $[23,25]$.

\section{MATERIALS AND METHODS}

\section{Chemicals and Reagents}

Synthesis and characterization of the compounds 1a-4a and 1 $\mathbf{b}-\mathbf{4 b}$ (Scheme 1) were performed as described earlier $[6,12]$. Their structure and purity was checked by their melting points, ${ }^{1} \mathrm{H}$ NMR, TLC (thin layer chromatography) and GC (gas chromatography) methods.

Quercetin (5), ethylenediaminetetraacetic acid disodium salt (EDTA), 2-deoxy-D-ribose (deoxyribose), 2thiobarbituric acid (TBA), dimethyl sulfoxide (DMSO), iron(II) sulfate $\left(\mathrm{FeSO}_{4}\right)$ and trichloroacetic acid (TCA) were purchased from Sigma-Aldrich (Budapest, Hungary). Other chemicals used were of analytical grade available if otherwise not specified. All solutions were freshly prepared using doubly distilled water. To control the $\mathrm{pH}$ value of prepared buffers Mettler Toledo MP $220 \mathrm{pH}$ meter and Mettler Toledo InLab 413 combined electrode was used. The absorbance was recorded with a Specord M40 (Carl Zeiss Jena, Germany) spectrometer. Each value is the average of three independent measurements.

\section{DEOXYRIBOSE DEGRADATION INITIATED BY IRON-DEPENDENT HYDROXYL RADICAL}

\section{Deoxyribose Degradation (Control)}

The mixture of deoxyribose $(9 \mathrm{mM})$ dissolved in $30 \mathrm{mM}$ phosphate buffer $\mathrm{pH} 7.4$ containing $40 \mathrm{mM}$ sodium chloride, $20 \mu \mathrm{M} / 50 \mu \mathrm{M}$ hydrogen peroxide $\left(\mathrm{H}_{2} \mathrm{O}_{2}\right)$ and $30 \mu \mathrm{M}$ iron(II) sulphate $\left(\mathrm{FeSO}_{4}\right)$ was incubated at $37{ }^{\circ} \mathrm{C}$ for 10 minutes. The reaction was started by the addition of $\mathrm{FeSO}_{4}$ and degradation of deoxyribose was determined by spectrophotometric measurement of the TBA-reactive substances. The incuba-

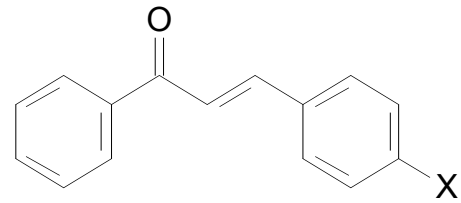

1

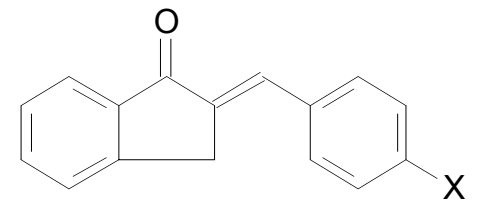

2

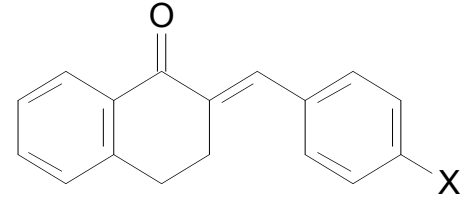

3

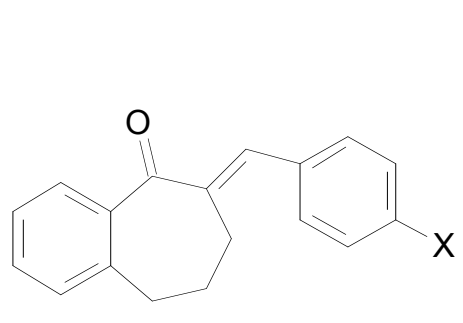

4<smiles>O=c1c(O)c(-c2ccc(O)c(O)c2)oc2cc(O)cc(O)c12</smiles>

Scheme 1. Structure of the investigated chalcones (1), E-2-(X-benzylidene)-1-indanones (2), -tetralones (3) and -benzosuberones (4), and quercetin (5). 
tion was performed in the presence of $1 \%(\mathrm{v} / \mathrm{v}) \mathrm{DMSO}$, too. The composition of the blanks was the same as above but $\mathrm{H}_{2} \mathrm{O}_{2}$ and $\mathrm{FeSO}_{4}$ were omitted.

\section{Deoxyribose Degradation in the Presence of Chalcones $(\mathbf{1 a}, \mathbf{b}-\mathbf{4 a}, \mathbf{b})$}

The incubations were carried out in the presence $(36 \mu \mathrm{M})$ or in the absence of EDTA. The reaction mixture contained: $30 \mathrm{mM}$ sodium phosphate buffer $\mathrm{pH} 7.4$ without EDTA or containing $36 \mu \mathrm{M}$ EDTA, $9 \mathrm{mM}$ deoxyribose, $40 \mathrm{mM}$ sodium chloride, $100 \mu \mathrm{M}$ or $200 \mu \mathrm{M}$ chalcone or quercetin (5) dissolved in DMSO corresponding to $1 \%(\mathrm{v} / \mathrm{v})$ of the total volume of the mixture, $20 \mu \mathrm{M}$ or $50 \mu \mathrm{M} \mathrm{H}_{2} \mathrm{O}_{2}$, and $30 \mu \mathrm{M}$ $\mathrm{FeSO}_{4}$. The control mixtures did not contain the investigated compounds, only the vehicle (DMSO). The composition of the blanks was the same as above but $\mathrm{H}_{2} \mathrm{O}_{2}$ and $\mathrm{FeSO}_{4}$ were omitted. The reactions were started by addition of $\mathrm{FeSO}_{4}$ and mixtures were incubated at $37^{\circ} \mathrm{C}$ for 10 minutes and in separate experiments for 4 hours. In these latter cases samples were taken at different $(0,20,40,60,80,100,120,140,160$, 180,200 , and 240 minutes) timepoints. Degradation of deoxyribose was characterized by spectrophotometric determination of the TBA-reactive substances.

\section{Determination of Thiobarbituric Acid Reactive Sub- stances (TBARS)}

The thiobarbituric acid reactivity was developed by mixing $1.0 \mathrm{ml}$ aliquot of the incubation mixtures with $0.5 \mathrm{ml}$ thiobarbituric acid reagent $(1 \%(\mathrm{w} / \mathrm{v})$ TBA dissolved in 50 $\mathrm{mM}$ sodium hydroxide solution) and $0.5 \mathrm{ml} 5.6 \%(\mathrm{w} / \mathrm{v})$ TCA followed by heating at $100{ }^{\circ} \mathrm{C}$ for 8 minutes. When the mixture was cooled and the developed chromogen was determined by reading the absorbance at $532 \mathrm{~nm}$ against appropriate blanks.

\section{RESULTS AND DISCUSSION}

Initially, the reaction was investigated using $30 \mu \mathrm{M}$ iron(II) ion and $20 \mu \mathrm{M} \mathrm{H}_{2} \mathrm{O}_{2}$ in the presence of $100 \mu \mathrm{M}$ chalcone analogues $(\mathbf{1} \mathbf{a}, \mathbf{b}-\mathbf{4 a}, \mathbf{b})$ using 10 minute incubation time. Under such conditions (excess of iron(II) ions over $\mathrm{H}_{2} \mathrm{O}_{2}$ ) the Fenton reaction is restricted to the quantitative oxidation of iron(II) ions by hydrogen peroxide [26].

$$
\begin{aligned}
& \mathrm{Fe}^{2+}+\mathrm{H}_{2} \mathrm{O}_{2}=\mathrm{Fe}^{3+}+\cdot \mathrm{OH}+\mathrm{OH}^{-} \\
& \mathrm{Fe}^{2+}+\cdot \mathrm{OH}=\mathrm{Fe}^{3+}+\mathrm{OH}^{-}
\end{aligned}
$$

Accordingly, iron(II) ions, deoxyribose and the tested compounds compete for the forming hydroxyl radicals.

Under such conditions the hydroxyl substituted compound 1b showed the most effective inhibition of deoxyribose degradation (Table 1). Increasing the chalcone concentration to $200 \mu \mathrm{M}$ resulted in a somewhat more effective antioxidant activity of the investigated compounds. Under these conditions compounds $\mathbf{2 a}, \mathbf{2} \mathbf{b}$ and $\mathbf{4 b}$ showed the most pronounced antioxidant effect (Table 1).

Increasing the $\mathrm{H}_{2} \mathrm{O}_{2}$ concentration to $50 \mu \mathrm{M}$ (excess of $\mathrm{H}_{2} \mathrm{O}_{2}$ over iron(II) ions) did not drastically change either the degree of oxidation of deoxyribose in the control samples or the antioxidant effect of the investigated compounds. Comparison of the corresponding results of the $20 \mu \mathrm{M}$ and $50 \mu \mathrm{M}$
$\mathrm{H}_{2} \mathrm{O}_{2}$ experiments showed a small but statistically significant increase of antioxidant effect of $\mathbf{1 a}$ and $\mathbf{4 a}$ used in $100 \mu \mathrm{M}$ concentration. Results of the two series of investigations showed the hydroxyl substituted $\mathbf{1 b}-\mathbf{4 b}$ to have somewhat more effective antioxidant activities. Quercetin (5) was statistically more effective antioxidant than any of the investigated chalcones under both investigated conditions (Table 1).

Performing the latter experiments in the presence of 36 $\mu \mathrm{M}$ EDTA resulted in a substantially reduced degradation of deoxyribose even in the control samples (Table 1). Reduced degradation of deoxyribose can be rationalized by the presence of the strong iron chelator EDTA [21,22]. At the same time the relative antioxidant activity of almost all the investigated compounds but the reference $\mathbf{5}$ increased in both concentrations. This observation suggest that complexation of iron ions by quercetin (5) - which can be substantially reduced by EDTA - plays an important role of antioxidant effect of 5 under the EDTA-free experimental conditions. In the presence of the strong iron chelator EDTA such effect of quercetin is diminished and its antioxidant (hydroxyl radical scavenger) activity becomes similar to that of the structurally related chalcones. The highest increase of antioxidant effect at the elevated $(200 \mu \mathrm{M})$ concentration was observed in the case of the benzosuberone derivatives $4 \mathbf{a}$ and $4 \mathbf{b}$, and the tetralone derivative 3a. Quercetin (5), the most effective tested compound, was also found to be more effective in the $200 \mu \mathrm{M}$ concentration (Table 1).

Time course of the Fenton-reaction initiated deoxyribose degradation was investigated using $50 \mu \mathrm{M} \mathrm{H}_{2} \mathrm{O}_{2}$ and $200 \mu \mathrm{M}$ test compounds without or in the presence of EDTA over a 240 minute time period. Application of long term incubation under such conditions (excess of $\mathrm{H}_{2} \mathrm{O}_{2}$ over iron(II) ions) provides the possibility to investigate whether chemical modification of the tested compounds by the Fenton reaction generated hydroxyl radicals results in formation of redox active derivatives which can initiate redox cycling (involving reduction of the iron(III) to iron(II) ions) and generation of hydroxyl radicals over the time of the extended incubation period [16]. On the other hand, reduction of iron(III) to iron (II) ions can diminish the iron(III)-catalyzed -non hydroxyl radical mediated- degradation of deoxyribose, which might be responsible for formation of some of the TBARS during the boiling phase of the method [27].

In the experiments performed without EDTA the level of TBA-reactive substances (TBARS) in the control incubations was found to be almost constant over the 240 minute period (Fig. 1A and 1B). This observation suggests that the initially formed TBARS and iron(III)-levels are stable under the control's conditions. According to the expectations, the initial antioxidant activity of the tested compounds could be well characterized by the short time determination of TBARS. Comparison of levels of TBARS of the control incubations at the 10 minute (ABS=0.705) (Table 1) and the 20 minute $(\mathrm{ABS}=0.765)$ (Fig. 1A) timepoints suggests that most of the Fenton-reaction initiated degradation of deoxyribose is taking place in the first 10 minutes of incubation. The zero minute level of TBARS (ABS $=0.761$ ) is very much the same as that of the 20 minute level (Fig. 1A) due to the heating of the freshly mixed samples at $100^{\circ} \mathrm{C}$ to obtain the TBA 


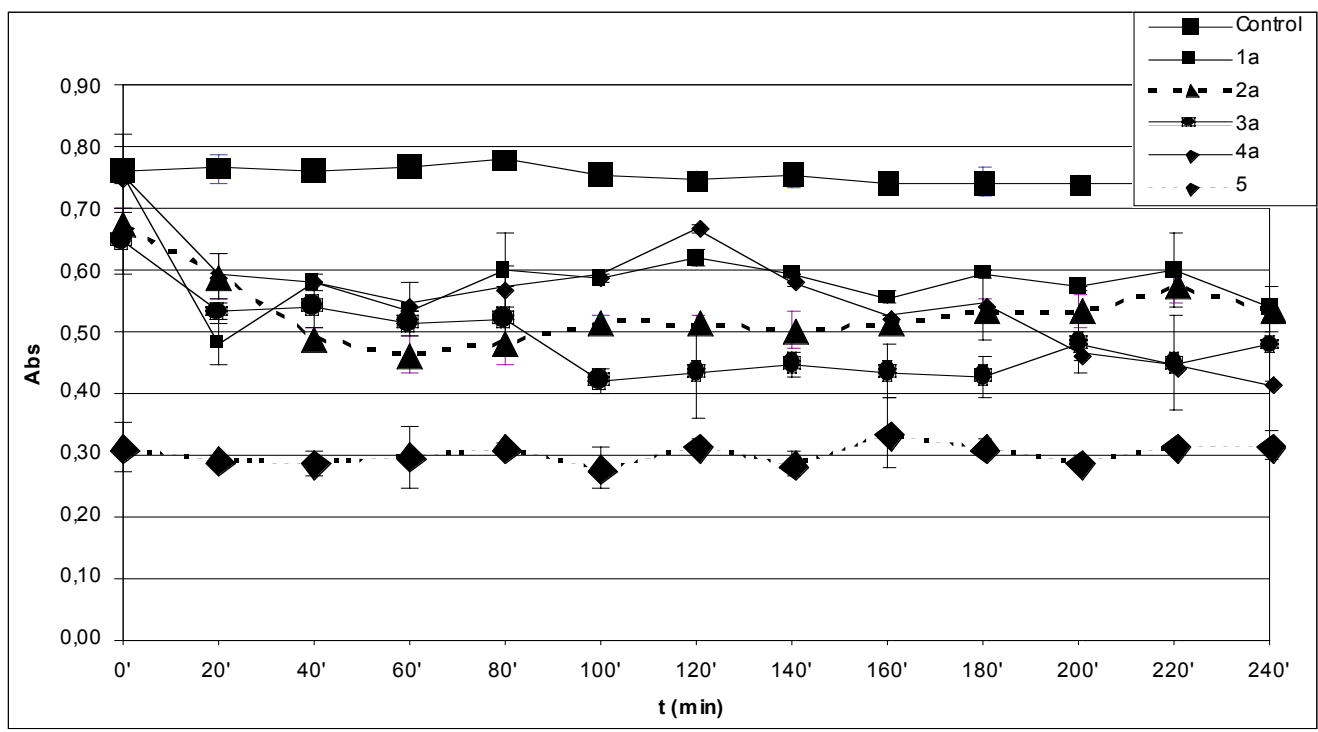

Fig. (1A). Time-course of degradation of deoxyribose in the presence of 1a-4a and quercetin (5) (200 $\mu \mathrm{M}) \mathrm{using} 50 \mu \mathrm{M} \mathrm{H} \mathrm{H}_{2}$.

*Each absorbance (Abs) $(\lambda=532 \mathrm{~nm})$ is the average of three parallel measurements \pm standard error. Details of incubation and derivatization is written in the Materials and Methods part.

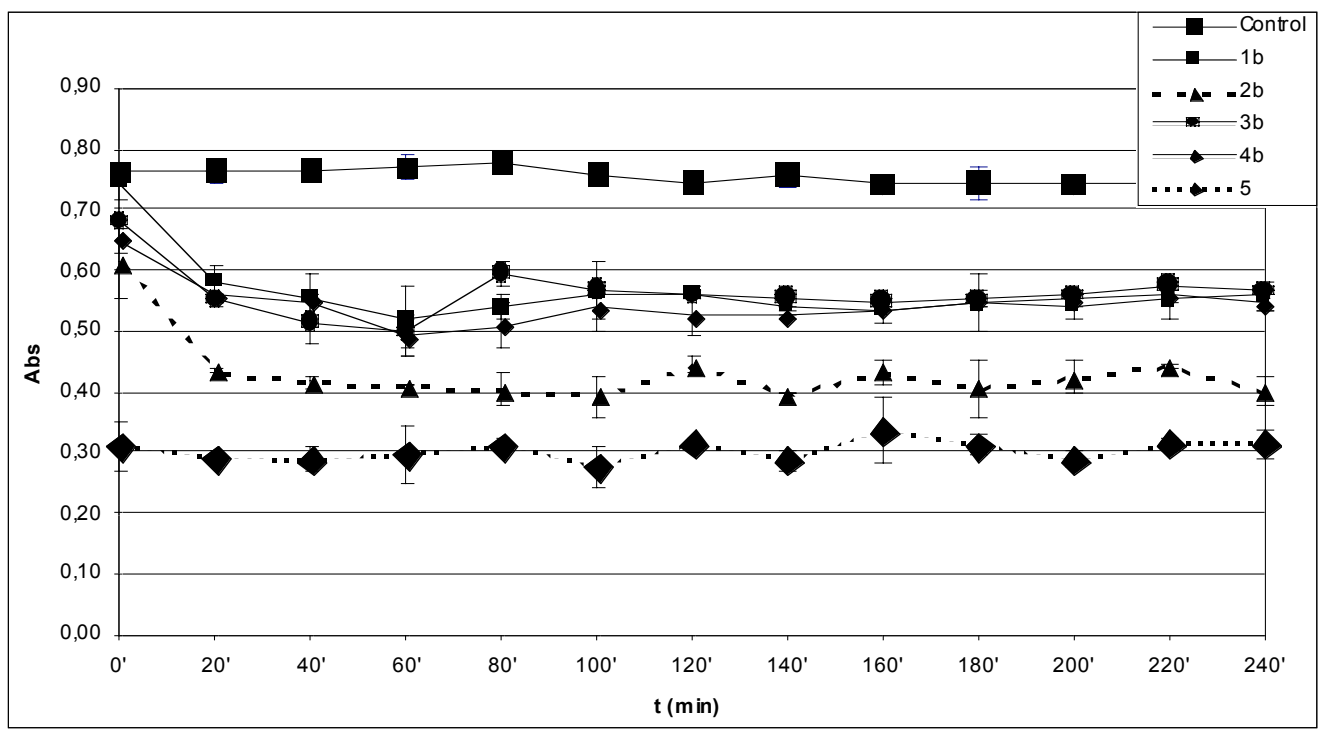

Fig. (1B). Time-course of degradation of deoxyribose in the presence of $\mathbf{1 b}-\mathbf{4 b}$ and quercetin (5) (200 $\mu \mathrm{M}) \mathrm{using} 50 \mu \mathrm{M} \mathrm{H} \mathrm{H}_{2} \mathrm{O}_{2}$.

*Each absorbance $(\mathrm{Abs})(\lambda=532 \mathrm{~nm})$ is the average of three parallel measurements \pm standard error. Details of incubation and derivatization is written in the Materials and Methods part.

chromogen. It is also worth mentioning that the zero minute level of TBARS is rather close to the control level in the case of all investigated compounds but $\mathbf{5}$ (Fig. 2A and B). This latter observation can be considered as the result of formation of iron-quercetin (5) complex [28] which results in reduced extent of deoxyribose degradation in "site-specific" degradation reactions.

Among the hydroxyl substituted compounds $\mathbf{1 b}-\mathbf{4 b}$ the indanone derivative $\mathbf{2 b}$ was found to be the most effective antioxidant (Fig. 1B). The TBARS level remained almost constant for each investigated compound from the 20 minute timepoint over the 240 minute period (Fig. 1B). On the contrary, the TBARS levels in the incubation mixtures of the methoxy substituted analogues 1a-4a slightly changed during the prolonged incubation time (Fig. 1A). For example, 3a and $4 \mathbf{a}$ displayed a significantly reduced TBARS levels after the 80 minute and 120 minute timepoints, respectively. These observations suggest redox activities that result in decrease of the TBA-reactive derivatives in the incubation systems.

Fenton-reaction initiated degradation of deoxyribose of the control incubations in the presence of EDTA $(36 \mu \mathrm{M})$ 
Table 1. Degradation of Deoxyribose in the Presence of Chalcones (1a,1b), Cyclic Chalcone Analogues (2a,2b,3a,3b,4a,4b) and Quercetin (5) Using $20 \mu \mathrm{M} \mathrm{H}_{2} \mathrm{O}_{2} ; 50 \mu \mathrm{M} \mathrm{H}_{2} \mathrm{O}_{2}$; and $36 \mu \mathrm{M}$ EDTA + $50 \mu \mathrm{M} \mathrm{H}_{2} \mathrm{O}_{2}$. (Incubation Time: 10 Minute)*

\begin{tabular}{|c|c|c|c|c|}
\hline Test Compound & $\begin{array}{c}\text { Concentration of test Com- } \\
\text { pound }(\mu \mathrm{M})\end{array}$ & $20 \mu \mathrm{M} \mathrm{H}_{2} \mathrm{O}_{2}$ & $50 \mu \mathrm{M} \mathrm{H} \mathbf{H}_{2} \mathbf{O}_{2}$ & $36 \mu \mathrm{M}$ EDTA $+50 \mu \mathrm{M} \mathrm{H}_{2} \mathrm{O}_{2}$ \\
\hline & & Absorbance & Absorbance & Absorbance \\
\hline Control & - & $0,705 \pm 0,033$ & $0,695 \pm 0,003$ & $0,356 \pm 0,015$ \\
\hline 1a & $200 \mu \mathrm{M}$ & $0,592 \pm 0,041$ & $0,615 \pm 0,017$ & $0,255 \pm 0,014$ \\
\hline $2 a$ & $100 \mu \mathrm{M}$ & $0,701 \pm 0,032$ & $0,674 \pm 0,028$ & $0,310 \pm 0,035$ \\
\hline 2a & $200 \mu \mathrm{M}$ & $0,554 \pm 0,029$ & $0,557 \pm 0,006$ & $0,293 \pm 0,016$ \\
\hline $4 a$ & $200 \mu \mathrm{M}$ & $0,631 \pm 0,017$ & $0,561 \pm 0,001$ & $0,245 \pm 0,029$ \\
\hline $1 \mathrm{~b}$ & $100 \mu \mathrm{M}$ & $0,571 \pm 0,032$ & $0,644 \pm 0,061$ & $0,243 \pm 0,037$ \\
\hline $1 \mathrm{~b}$ & $200 \mu \mathrm{M}$ & $0,550 \pm 0,013$ & $0,528 \pm 0,011$ & $0,236 \pm 0,027$ \\
\hline $2 \mathbf{b}$ & $100 \mu \mathrm{M}$ & $0,622 \pm 0,019$ & $0,621 \pm 0,030$ & $0,274 \pm 0,004$ \\
\hline $2 b$ & $200 \mu \mathrm{M}$ & $0,531 \pm 0,011$ & $0,538 \pm 0,014$ & $0,248 \pm 0,002$ \\
\hline $3 \mathbf{b}$ & $100 \mu \mathrm{M}$ & $0,671 \pm 0,019$ & $0,677 \pm 0,001$ & $0,280 \pm 0,028$ \\
\hline $3 \mathbf{b}$ & $200 \mu \mathrm{M}$ & $0,553 \pm 0,012$ & $0,651 \pm 0,012$ & $0,259 \pm 0,018$ \\
\hline
\end{tabular}

*Each absorbance $(\lambda=532 \mathrm{~nm})$ is the average of three parallel measurements \pm standard error. Details of incubation and derivatization is written in the Materials and Methods part.

resulted in significantly lower level of TBARS than that of without EDTA. Similar to the experiments performed without EDTA, the level of TBARS in the control incubations was found to be almost constant over the 240 minute period (Fig. 2A and B). Under such conditions the zero time level of TBARS is also very much the same in all incubations but in that performed in the presence of $\mathbf{5}$, where it is statistically lower.

The TBARS levels in the incubations of the hydroxyl substituted $\mathbf{1 b}-\mathbf{4 b}$ performed in the presence of EDTA are comparable to that of the reference $\mathbf{5}$ in each case but the open-chain 1b (Fig. 2B). This observation also underlines importance of formation of iron(II)-quercetin (5) complex in the significantly higher antioxidant effect of $\mathbf{5}$ under the EDTA-free experimental conditions. Similar investigation of the methoxy substituted 1a-4a showed all the incubations but that with 4 a to have TBARS levels similar to that of with $\mathbf{5}$ (Fig. 2A). It was found that the TBARS level of the incubation with 4a showed an increase over the 60-120 minute pe- riod followed by significant decrease over the rest of the incubation time (Fig. 2A). In order to get a better understanding of the observed prooxidant effect of $\mathbf{4 a}$ ethyl acetate extract of the 120 minute incubation sample was investigated by GC-MS. GC-MS analysis of the ethyl acetate extract could not indicate presence of any derivative of the parent compound. Further studies are needed to provide experiment-based explanation of this observation. Such a prooxidant activity of $\mathbf{4 a}$ is characteristically different from the results obtained with the respective hydroxyl substituted $\mathbf{4 b}$.

In summary it was demonstrated that scope of the original "test-tube" assay for evaluation of antioxidant properties of potential antioxidants based on the degree of Fentonreaction initiated degradation of deoxyribose is valid but limited. Although the initial antioxidant activity of the tested compounds can be well characterized by the short time determination of TBA-reactive substances, complex forming activities that can modify microspeciation and reactivity of iron ions can lead to different antioxidant efficiency of the 


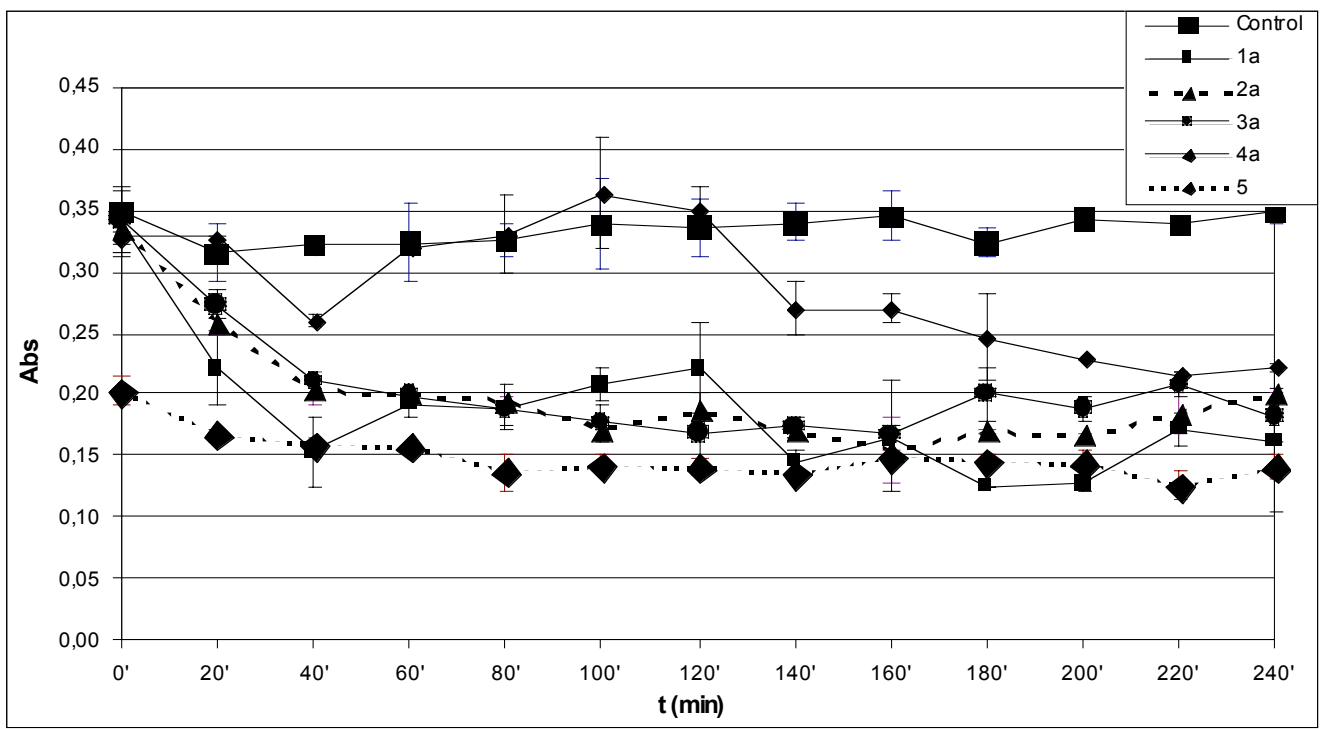

Fig. (2A). Time-course of degradation of deoxyribose in the presence of 1a-4a and quercetin (5) (200 $\mu \mathrm{M})$ using $36 \mu \mathrm{M}$ EDTA and $50 \mu \mathrm{M}$ $\mathrm{H}_{2} \mathrm{O}_{2}$.

*Each absorbance $(\mathrm{Abs})(\lambda=532 \mathrm{~nm})$ is the average of three parallel measurements \pm standard error. Details of incubation and derivatization is written in the Materials and Methods part.

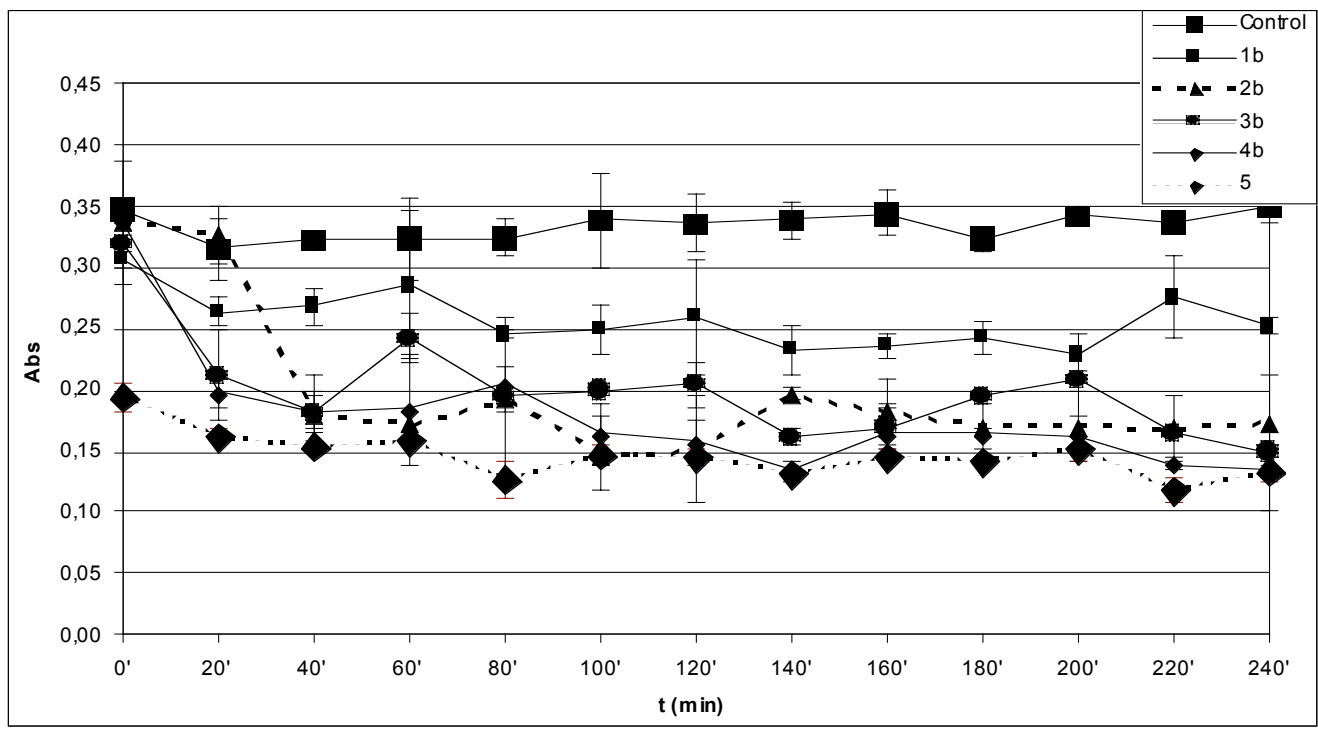

Fig. (2B). Time-course of degradation of deoxyribose in the presence of $\mathbf{1 b}-\mathbf{4 b}$ and quercetin (5) (200 $\mu \mathrm{M})$ using $36 \mu \mathrm{M}$ EDTA and $50 \mu \mathrm{M}$ $\mathrm{H}_{2} \mathrm{O}_{2}$.

*Each absorbance (Abs) $(\lambda=532 \mathrm{~nm})$ is the average of three parallel measurements \pm standard error. Details of incubation and derivatization is written in the Materials and Methods part.

tested substances. Chemical modification of the tested substances can result formation of derivatives that can initiate further redox activities under specific experimental conditions that can convert short-term "antioxidants" to "prooxidants" on longer observation time. To have a more comprehensive evaluation of antioxidant/prooxidant activities of xenobiotics long term investigations are recommended with/without of transition metal chelating agents (e.g., EDTA) that can modify microspeciation of iron ions. On the other hand, the added chelating agents can also act as com- petitive hydroxyl radical scavengers in the Fenton-type test systems.

\section{ACKNOWLEDGEMENT}

This study was supported by the Faculty of Medicine Research Fund (AOK-KA 34039-12/2009), University of Pécs. The authors express their sincere thanks to Szilárd Molnár (South-Transdanubian Environmental Protection Inspectorate, H-7634 Pécs-Cserkút, Hungary) for performing the GC-MS measurements in his laboratory, and to 
Zsuzsanna Moravecz (University of Pécs) for her excellent technical assistance.

\section{REFERENCES}

[1] Harborne, J.B. In Plant Flavonoids in Biology and Medicine: Biochemical, pharmacological and Structure-Activity Relationships. Cody, V., Middleton, E.Jr., Harborne, J.B.S. Eds.; Alan R. Liss: New York, 1986; pp. 15-24.

[2] Middleton, E.Jr.; Kandaswami, C.; Theoharides, T.C. The effect of plant flavonoids on mammalian cells: Implications for inflammation, heart disease, and cancer. Pharmacol. Rev., 2000, 52, 673751 .

[3] Nakamura, Y.; Watanabe, S.; Miyake, N.; Kohno, H.; Osawa, T. Dihydrochalcones: evaluation as novel radical scavenging antioxidants. J. Agric. Food Chem., 2003, 51, 3309-12.

[4] Dimmock, J.R.; Elias, D.W.; Beazely, M.A.; Kandepu, N.M. Bioactivities of chalcones. Curr. Med. Chem., 1999, 6, 1125-49.

[5] Go, M.L.; Wu, X.; Liu, X.L. Chalcones: an update on cytotoxic and chemopreventive properties. Curr. Med. Chem., 2005, 12, 483-99.

[6] Dimmock, J.R.; Kandepu, N.M.; Nazarali, A.J.; Kowalchuk, T.P.; Motaganahalli, N.; Quail, J.W.; Mykytiuk, P.; Audette, G.F.; Prasad, L.; Perjési, P.; Allen, T.M.; Santos, C.L.; Sydlowski, J.; De Clercq, E.; Balzarini, J. Conformational and quantitative structureactivity relationship study of cytotoxic 2-arylidenebenzocycloalkanones. J. Med. Chem., 1999, 42, 1358-66.

[7] Dimmock, J.R.; Zello, G.A.; Oloo, E.O.; Quail, J.W.; Kraatz, H.B.; Perjési, P.; Aradi, F.; Takács-Novák, K.; Allen, T.M.; Santos, C.L.; Balzarini, J.; De Clercq, E.; Stables, J.P. Correlations between cytotoxicity and topography of some 2-arylidenebenzocyclanones determined by X-ray crystallography. J. Med. Chem., 2002, 45, 3103-11.

[8] Perjési, P.; Das, U.; De Clerq, E.; Balzarini, J.; Kawase, M.; Sakagami, H.; Stables, J.P.; Lorand, T.; Rozmer, Zs.; Dimmock, J.R. Design, synthesis and antiproliferative activity of some 3benzylidene-2,3-dihydro-1-benzopyran-4-one which display selective toxicity for malignant cells. Eur. J. Med. Chem., 2008, 43, 831-49.

[9] Monostory, K.; Tamási, V.; Vereczkey, L.; Perjési, P. Study on CYPA1 inhibitory action of 4'-methoxybenzylidene-benzosuberone and some related cyclic chalcone derivatives. Toxicology., 2003, 184, 203-10.

[10] Rozmer, Zs.; Berki, T.; Perjési, P. Different effects of two cyclic chalcone analogues on cell cycle of Jurkat $\mathrm{T}$ cells. Toxicol. In vitro, 2006, 20, 1354-62.

[11] Perjési, P.; Kubalkova, J.; Chovanova, Z.; Marekova, M.; Rozmer, Zs.; Fodor, K.; Chavkova, Z.; Tomeskova, V.; Guzy, J. Comparison of effects of some cyclic chalcone analogues on selected mitochondrial functions. Pharmazie, 2008, 63, 899-903.

[12] Guzy, J.; Vaskova-Kubalkova, J.; Rozmer, Zs.; Fodor, K.; Marekova, M.; Poskrobova, M.; Perjesi, P. Activation of oxidative stress response by hydroxyl systituted chalcones and cyclic chalcone analogues in mitochondria. FEBS Lett., 2010, 584, 567-70.

[13] Halliwell, B.; Gutteridge, J.M.C.; Aruoma, O.I. The deoxyribose method: A simple "test-tube" assay for determination of rate constants for reactions of hydroxyl radicals. Anal. Biochem., 1987, 165, 215-9.

[14] Cheeseman, K.H.; Beavis, A.; Esterbauer, H. Hydroxyl-radicalinduced iron-catalysed degradation of 2-deoxyribose. Biochem. J., 1988, 252, 649-53.

[15] Grootveld, M.; Halliwell, B.; Hill, H.A.O. An aromatic hydroxylation assay for hydroxyl radicals utilizing high-performance liquid chromatography (HPLC). Use to investigate the effect of EDTA on the Fenton reaction. Free Radical Res., 1986, 1, 243-50.

[16] Gregus, Z.; Klaassen, C.D. In Casarett and Doull's Toxicology. The Basic Science of Poisons; Klaassen, C.D. Ed.; McGraw-Hill: New York, 2001, Chapter 3, pp 35-81.

[17] Parkinson, A. In Casarett and Doull's Toxicology. The Basic Science of Poisons; Klaassen C.D. Ed.; McGraw-Hill: New York, 2001, Chapter 6, pp 133-224.

[18] Cheng, Z.; Li, Y.; Chang, W. Kinetic deoxyribose degradation assay and its application in assessing the antioxidant activities of phenolic compounds in a Fenton-type reaction system. Anal. Chim. Acta, 2003, 478, 129-37.

[19] Rozmer, Zs.; Perjési, P. Néhány nem-szteroid gyulladáscsökkentő hatásának vizsgálata a 2-deoxi-D-ribóz Fenton-reakció iniciálta degradációjára. Acta Pharm. Hung., 2005, 75, 87-93.

[20] Winterbourn, C.C. Factors that influence the deoxyribose oxidation assay for Fenton reaction products. Free Rad. Biol. Med., 1991, 11, 353-60.

[21] Galey, J.-B. In Antioxidants in Disease Mechanisms and Therapy; Sies H. Ed.; Academic Press: San Diego, 1997, pp 167-203.

[22] Halliwell, B. In Antioxidants in Disease Mechanisms and Therapy; Sies H. Ed.; Academic Press: San Diego, 1997, pp 3-20.

[23] Chobot, V. Simultaneous detection of pro-and antioxidative effects in the variants of the deoxyribose degradation assay. J. Agric. Food Chem., 2010, 58, 2088-94.

[24] Formica, J.V.; Regelson, W. Review of the biology of quercetin and related bioflavonoids. Food Chem. Toxicol., 1995, 33, 106180 .

[25] Pietta, P.G. Flavonoids as antioxidants. J. Nat. Prod., 2000, 63, 1035-42.

[26] Kremer, M.L. Mechanism of the Fenton reaction. Evidence for a new intermediate. Phys. Chem. Chem. Phys., 1999, 1, 3595-05.

[27] Genaro-Mattos, T.C.; Dalvi, L.T.; Oliveira, R.G.; Ginani, J.S.; Hermes-Lima, M. Reevaluation of the 2-deoxyribose assay for determination of free radical formation. Biochim. Biophys. Acta., 2009, 1790, 1636-42.

[28] Hajji, H.E.; Nkhili, E.; Tomao, V.; Dangles, O. Interactions of quercetin with iron and copper ions: complexation and autoxidation. Free Radical Res., 2006, 40, 303-20. 